\title{
As Relações Entre Saber e Poder em Testes Psicodiagnósticos a partir de M. Foucault ${ }^{*}$
}

(The Relations Between Knowledge and Power in Psychodiagnostic Tests based on M. Foucault)

\author{
Monica CARON \\ (Departamento de Lingüistica Aplicada/IEL - UNICAMP/FAPESP)
}

\begin{abstract}
In this article my main objective is to approach some questions related to the tests used in psychodiagnostics processes of children who are considered as having learning difficulties. Having the book Discipline and Punish (1975/1986) by Foucault as theoretical basis, I intend to investigate the hypothesis that the child is considered ill or abnormal due to the factors related to imposed norms and not to organic aspects and/ or neurological pathology. My interest is to analyse the signs that allow us to point out the written language conception of tests. This language is expected and privileged, however it may not be the language that the child uses and experiences every day.
\end{abstract}

KEY-WORDs: learning difficulties; psychological tests; psychodiagnostics.

RESUMO: No presente artigo tenho o objetivo de abordar algumas questões relativas aos testes utilizados nos processos psicodiagnósticos de crianças consideradas portadoras de dificuldades de aprendizagem. Tomando como pano de fundo histórico, principalmente, o livro de Foucault Vigiar e Punir (1975/1986), pretendo investigar a bipótese de que a criança é considerada doente, anormal devido a fatores relacionados às normas impostas e não a organicidade elou patologia neurológica. Interessa-me refletir sobre os indícios que permitem apontar a concepção de linguagem escrita subjacente aos testes, linguagem esperada e privilegiada, mas que pode não ser a linguagem que a criança usa, vive e experiencia.

PalavRas-Chave: dificuldades de aprendizagem; testes psicológicos; psicodiagnósticos.

\footnotetext{
* Este trabalho teve apoio da FAPESP.
}

D.E.L.T.A., 21:2, 2005 (215-236) 


\section{Introdução}

No texto tenho o objetivo de refletir sobre algumas questões relativas aos testes utilizados nos processos psicodiagnósticos - de crianças consideradas portadoras de dificuldades de aprendizagem - tomando como pano de fundo histórico, principalmente, o livro Vigiar e Punir de Foucault (1975/ 1986).

Historicamente, tem sido negado ao grupo de crianças consideradas portadoras de dificuldades de aprendizagem o livre acesso à escola, à escrita e a uma formação consistente. Rotuladas como doentes essas crianças formam um grupo excluído e isolado nos contextos educacionais, grupo enviado às Salas Especiais e aos hospitais para investigações neuro e psicológicas.

A título de hipótese, pretendo investigar se as crianças incluídas em tal categoria nosográfica são consideradas doentes/anormais devido a fatores relacionados às normas impostas pelos testes e não a organicidade e/ou patologia neurológica. Para tanto, interessa-me, sobretudo, investigar os indícios que permitem apontar a concepção de linguagem escrita subjacente à montagem e avaliação dos testes, linguagem que a Psicologia (representada na figura do psicólogo e, mais concretamente, nos testes psicológicos) espera e privilegia, mas que pode não ser a linguagem que a criança usa, vive e experiencia.

Inicialmente, discutirei as principais idéias do livro de Foucault (1975/ 1986) e destacarei alguns aspectos que considero importantes para a análise acerca da relação entre o poder da normalização e o saber da Psicologia na elaboração dos psicodiagnósticos ("frutos" dos testes). Em seguida apresentarei a metodologia de análise utilizada, o Paradigma Indiciário, e o corpus, do qual farei um breve relato sobre o processo de coleta. $\mathrm{Na}$ análise dos dados apresentarei autores cujas reflexões considero importantes para a argumentação que pretendo desenvolver.

\section{Sobre o livro Vigiar e Punir (1975/1986) de Foucault}

No livro, Foucault busca entender as condições histórico-sociais de possibilidade da modernidade clássica, ou sociedade industrial. Muitas das questões que estudou são ainda hoje relevantes e a elas somam-se os novos dispositivos decorrentes das problemáticas da modernidade. O objetivo do 
livro, nas palavras do autor, é apresentar “(...) uma história correlativa da alma moderna e de um novo poder de julgar; uma genealogia do atual complexo científico-judiciário" (p. 26). A punição é concebida como uma função social complexa e os métodos punitivos são analisados como técnicas que têm sua especificidade no campo mais geral dos outros processos de poder. Ao invés de tratar a história das Ciências Humanas e do direito penal como dois domínios separados cujo encontro teria sobre ambas um efeito útil, o autor procura verificar se há uma matriz comum, se elas se originam do mesmo processo de formação epistemológico-jurídico. Colocando a tecnologia do poder no princípio da humanização da penalidade e do conhecimento do homem, o autor investiga a hipótese de a entrada da alma e de um saber científico, na prática judiciária, como efeito de uma transformação na maneira como o próprio corpo é investido pelas relações de poder.

De acordo com Foucault (1975/1986), com o passar do tempo as práticas punitivas se tornaram recatadas e não deveriam mais tocar no corpo. Se o fizessem, que fosse o mínimo possível, pois não é mais ao corpo que se orienta a punição, é à alma: "à expiação que tripudia sobre o corpo deve suceder um castigo que atue, profundamente, sobre o coração, o intelecto, a vontade, as disposições” (pp. 20-21), a subjetividade. Segundo o autor, esse processo é marcado por rápidas e sutis substituições que se introduziram no sistema penal, na legislação e nas formas de punição e julgamento. Sob o nome de crimes e delitos são sempre julgados os objetos jurídicos definidos pelo código, mas, “(...) julgam-se também as paixões, os instintos, as anomalias, as enfermidades, as inadaptações” (Foucault 1975/1986: 21).

Apontando a singularidade da justiça penal moderna, carregada de elementos extra-jurídicos e juízes paralelos, como peritos psiquiátricos ou psicólogos, magistrados da aplicação de penas e educadores, Foucault considera que a justiça criminal funciona e se justifica apenas “(...) por essa perpétua referência a outra coisa que não é ela mesma, por essa incessante reinscrição nos sistemas não jurídicos" (p. 25), por essa requalificação do saber. $\mathrm{Na}$ análise foucaultiana, uma das funções do discurso da criminologia, da antropologia criminal e do laudo psiquiátrico está localizada no processo que busca introduzir

(...) as infrações no campo dos objetos susceptíveis de um conhecimento científico, [busca] dar aos mecanismos da punição legal um poder justificável não mais simplesmente sobre as infrações, mas sobre os indivíduos; não mais sobre o que eles fizeram, mas sobre aquilo que eles são, serão, ou possam ser (Foucault 1975/1986: 22). 
Considerada a inscrição do poder sobre o corpo, o autor relaciona este poder à produção de um saber já que estes estão diretamente implicados, pois o poder produz saber e não simplesmente favorece-o porque o serve ou amplia-o porque é útil. De sua perspectiva, “(...) não há relação de poder sem constituição correlata de um campo de saber, nem saber que não suponha e não constitua ao mesmo tempo relações de poder" (Foucault 1975/1986: 28-30).

No século XVIII, de acordo com Foucault (1975/1986), uma nova mentalidade propôs a lei fundamental segundo a qual o castigo deve ter a bumanidade como medida. Nesta época, operou-se uma transformação geral de atitude (foi imposta uma suavidade à punição) que talvez pertença ao campo do espírito e da subconsciência ou ao reconhecimento da condição humana dos infratores, mas que, na hipótese do autor,

(...) significa uma adaptação e harmonia dos instrumentos que se encarregam de vigiar o comportamento cotidiano das pessoas, sua identidade, atividade, gestos aparentemente sem importância; significa uma outra política a respeito dessa multiplicidade de corpos e forças que uma população representa (Foucault 1975/1986: 73).

Definiu-se assim uma tendência para uma justiça mais desembaraçada, mais inteligente, e para uma vigilância penal mais atenta do corpo social. A reforma nasceu não devido a uma nova sensibilidade, mas sim em função de uma outra política relativa às ilegalidades, pois estas lançaram o indivíduo, de fato, contra o corpo social. Nesse processo vemos o deslocamento do direito de punir: da vingança do soberano para a defesa da sociedade. Na prática penal, o saber psicológico passou a substituir a jurisprudência casuística.

Operou-se a passagem do punir para o vigiar e a nova conjuntura política resultou no reencontro de duas linhas divergentes de objetivação que se formaram no século XVIII: a que rejeitava o criminoso para o lado de uma natureza contra a natureza e a que procurava controlar a delinqüiencia por uma anatomia calculada das punições. Os processos de objetivação nasceram nas próprias táticas do poder e na distribuição de seu exercício e a investigação, segundo Foucault (1975/1986), “(...) da nova arte de punir mostra bem a substituição da semiotécnica punitiva por uma nova política do corpo" (p. 93).

Com as mudanças ocorridas ao longo do tempo, o corpo dos condenados passou a ser um bem social, objeto de uma apropriação coletiva e útil, 
deixando de ser uma propriedade do rei. Foucault (1975/1986) aponta que sinais-obstáculos devem constituir o novo arsenal das penas e têm de obedecer as seguintes condições: "ser tão pouco arbitrários quanto possível" (p. 94), pois o castigo deve decorrer do crime para "(...) que a lei pareça ser uma necessidade das coisas, e que o poder aja mascarando-se sob a força suave da natureza" (p. 95). Desse modo, antes de ser concebido como objeto de ciência, o criminoso é visto como elemento de instrução.

$\mathrm{Na}$ análise foucaultiana, um corpo que pode ser submetido, utilizado, transformado e aperfeiçoado é um corpo dócil. Para o autor, foi durante a época clássica que houve essa descoberta do corpo como alvo de poder, o que definiu o nascimento de uma anatomia política que é também uma mecânica de poder, pois determina um modo possível de se dominar o corpo dos outros “(...) não simplesmente para que façam o que se quer, mas para que operem como se quer, com as técnicas, segundo a rapidez e a eficácia que se determina" (p. 127). A exploração econômica cinde a força e o produto do trabalho e "(...) a coerção disciplinar estabelece no corpo o elo coercitivo entre uma aptidão aumentada e uma dominação acentuada" (p. 127). O surgimento dessa nova anatomia política não deve ser entendido como uma descoberta súbita: a encontramos em funcionamento nos colégios, nas escolas primárias, no espaço hospitalar e na reestruturação da organização militar. As técnicas essenciais que compõem essa nova anatomia política se generalizaram facilmente. Sempre minuciosas, íntimas, importantes

(...) porque definem um certo modo de investimento político e detalhado do corpo, uma nova "microfísica" do poder; e porque não cessaram, desde o século XVII, de ganhar campos cada vez mais vastos, como se tendessem a cobrir o corpo social inteiro (...) [descrevê-las] implicará na demora sobre o detalhe e na atenção às minúcias: sob as mínimas figuras, procurar não um sentido, mas uma precaução; recolocá-las não apenas na solidariedade de um funcionamento, mas na coerência de uma tática (Foucault 1975/1986: 128).

A época clássica forneceu instrumentos mais precisos para operar o poder sobre os corpos, mudou sua escala, ecoando no cálculo do infinitamente pequeno e na descrição das características mais sutis dos seres humanos. Também derivam dessa nova anatomia política "(...) todas as meticulosidades da educação cristã, da pedagogia escolar ou militar, de todas as formas, finalmente, de treinamento" (Foucault, 1975/1986: 129), da disciplina, da estrutura dos códigos civis e militares e das normas institucionais. 
A disciplina, na acepção do autor, atua em primeiro lugar na distribuição dos indivíduos no espaço. Assim, também o espaço escolar se incrementou, principalmente após o ano de 1762, e a classe tornou-se homogênea: ordenaram-se fileiras de alunos na sala, nos corredores, nos pátios; alinharamse as classes por idade, umas depois das outras; ordenaram-se os assuntos ensinados, as questões passaram a ser tratadas segundo o que se acreditava ser uma ordem de dificuldade crescente; marcou-se uma hierarquia do saber e da capacidade. Para o autor, uma das grandes modificações técnicas do ensino elementar foi essa organização de um espaço serial, o que possibilitou ao espaço escolar funcionar como uma máquina de ensinar, vigiar, hierarquizar e recompensar. A esse poder disciplinar corresponde um tempo linear, um tempo claro, simples e direto, revelado pelos métodos disciplinares. Pouco a pouco, esse tempo disciplinar passa a se impor sobre a prática pedagógica, especificando o tempo de formação, desvinculando-o do tempo adulto, tempo do ofício adquirido. O corpo tornou-se alvo de novos mecanismos do poder e se apresentou às novas formas de saber, processo que Foucault (op. cit.) denominou codificação instrumental do corpo.

Entre os efeitos da disciplina o autor considera o fato de que ela origina

(...) uma individualidade dotada de quatro características: é celular (pelo jogo da repartição espacial), é orgânica (pela codificação das atividades), é genética (pela acumulação do tempo), é combinatória (pela composição das forças) (Foucault 1975/ 1986: 150).

Além disso, a disciplina origina técnicas, que são: a construção de quadros; a prescrição de manobras; a imposição de exercícios; e, para realizar a combinação das forças, a organização de táticas. O poder disciplinar não amarra as forças para reduzi-las, mas procura ligá-las para multiplicá-las e utilizá-las num todo. Para Foucault (1975/1986) o poder disciplinar produz indivíduos, pois a disciplina é a técnica de um poder que toma os indivíduos como objetos e como instrumentos de seu exercício. Para o autor,

as disciplinas marcam o momento em que se efetua o que se poderia chamar a troca do eixo político da individualização (...) Quanto mais o homem é detentor de poder ou de privilégio, tanto mais é marcado como indivíduo, por rituais, discursos, ou representações plásticas (...) uma individualização "ascendente". Num regime disciplinar, a individualização, ao contrário, é "descendente": à medida que o poder se torna mais anônimo e mais funcional, aqueles sobre os quais se exerce tendem a ser mais fortemente individualizados; e por fiscalizações mais que por cerimônias, por observações mais que por relatos comemorativos, por medidas comparativas que 
têm a "norma" como referência, e não por genealogias que dão os ancestrais como pontos de referência; por "desvios” mais que por proezas (Foucault 1975/1986: 171).

O autor atribui o êxito do poder disciplinar ao fato de este fazer "(...) uso de instrumentos simples: o olhar hierárquico, a sanção normalizadora e sua combinação num procedimento que lhe é específico, o exame" (p. 153). Fez-se necessário uma escala para o olhar disciplinar já que o exercício da disciplina exige técnicas que induzam a efeitos de poder, o poder disciplinar. Nos sistemas disciplinares, ao lado das punições copiadas ao modelo judiciário (multas, açoite, masmorra), privilegia-se “(...) as punições que são da ordem do exercício - aprendizado intensificado, multiplicado, muitas vezes repetido" (Foucault 1975/1986: 160).

É nesse processo que Foucault situa o surgimento do saber da Psicologia no tocante às técnicas de investigação e diagnóstico, apontando que "todas as ciências, análises ou práticas com radical "psico", têm seu lugar nessa troca histórica dos processos de individualização” (p. 172). Algumas das operações consideradas pelo autor características da penalidade disciplinar se assemelham às técnicas dos testes psicológicos:

em primeiro lugar, a qualificação dos comportamentos e dos desempenhos a partir de dois valores opostos do bem e do mal; (...) temos uma distribuição entre pólo positivo e pólo negativo; todo o comportamento cai no campo das boas e das más notas, dos bons e dos maus pontos. É possível, além disso, estabelecer uma quantificação e uma economia traduzida em números (Foucault 1975/1986: 161).

Essa divisão a partir de classificações ou graus marca os desvios, hierarquiza as qualidades, as competências e as aptidões; mas também castiga e recompensa.

Próximo ao fim do século XVIII, emergiu o que o autor coloca sob a sigla de ciências clínicas: no campo do saber entrou o indivíduo (e não mais a espécie); no funcionamento geral do discurso científico entrou a descrição do interrogatório, a anamnese. Para Foucault (1975/1986), as técnicas de anotação (registro, constituição de processos, distribuição e colocação em colunas) tiveram importância decisiva na liberação epistemológica das ciências do indivíduo. Esse aparelho de escrita, que acompanha o exame, inaugura duas possibilidades correlacionadas: de um lado, a constituição do indivíduo como objeto descritível, analisável e, de outro, a constituição de um sistema comparativo que permite a medida de fenômenos globais. Dessa forma, foi possível manter, sob o controle de um saber permanente, 
as aptidões ou capacidades próprias do indivíduo, a descrição de grupos, a caracterização de fatos coletivos, a estimativa dos desvios dos indivíduos entre si e sua distribuição numa "população". O exame

cercado de todas as suas técnicas documentárias, faz de cada individuo um "caso": um caso (...) é o indivíduo tal como pode ser descrito, mensurado, medido, comparado a outros e isso em sua própria individualidade; e é também o indivíduo que tem que ser treinado e retreinado, tem que ser classificado, normalizado, excluído, etc. (Foucault 1975/1986.: 170).

Um dos possíveis modelos do sistema disciplinar compreende espaços fechados, vigiados em todos os seus pontos, indivíduos inseridos em lugares fixos, o controle dos menores movimentos, o registro de todos os acontecimentos

(...) onde o poder é exercido sem divisão, segundo uma figura hierárquica, contínua, onde cada indivíduo é constantemente localizado, examinado e distribuído entre os vivos, os doentes e os mortos - isso tudo constitui um modelo compacto do dispositivo disciplinar (Foucault 1975/1986: 174-175).

Esse sistema constante de registro e mensuração, o panóptico segundo o autor, teve como principal resultado a indução de um estado consciente e permanente de visibilidade. O panóptico assegurou o funcionamento automático do poder e permitiu estabelecer as diferenças, observar os sintomas, anotar os desempenhos (sem que houvesse imitação ou cópia), perceber as aptidões, apreciar os caracteres e estabelecer classificações rigorosas. Além disso, o panóptico determina a inserção dos corpos no espaço, a distribuição dos indivíduos em relação mútua, a organização hierárquica, a disposição dos centros e dos canais de poder, definindo seus próprios instrumentos e os modos de intervenção que devem utilizar os hospitais, as oficinas, as escolas e as prisões. Sempre que se tratar de uma multiplicidade de indivíduos a que se deve impor uma tarefa ou um comportamento, o esquema panóptico poderá ser utilizado. Neste sentido, de acordo com o autor, o panóptico pode constituir-se em aparelho de controle sobre seus próprios mecanismos, pois é um sistema privilegiado para tornar possível a experiência com homens.

O autor situa outros aspectos que derivam das instituições em níveis mais profundos, que são: a inversão funcional das disciplinas, que deve neutralizar os perigos, fixar as populações inúteis ou agitadas, evitar os inconvenientes de reuniões muito numerosas; o aumento da utilidade possível 
dos indivíduos; a ramificação dos mecanismos disciplinares; e a estatização dos mecanismos de disciplina, já que o poder policial deve se exercer " (...) "sobre tudo": não é entretanto a totalidade do Estado nem do reino como corpo visível e invisível do monarca; é a massa dos acontecimentos, das ações, dos comportamentos, das opiniões" (Foucault 1975/1986: 187-188). Para que esse poder possa ser exercido ele necessita uma permanente vigilância, exaustiva, onipresente, capaz de tornar tudo visível, mas com a condição de se tornar ela mesma invisível. Ao contrário dos métodos de escrita judiciária ou administrativa, o que é registrado são comportamentos, atitudes, virtualidades, suspeitas, em suma, o comportamento dos indivíduos. Na modalidade panóptica do poder as disciplinas corporais constituíram a base das liberdades formais e jurídicas. No fundamento ideal do direito e do poder político, o panoptismo constituía o processo técnico, universalmente difundido, da coerção. Vêem-se, deste modo, as disciplinas como instrumento de exclusão, pois elas atuam como

(...) uma espécie de contradireito. Elas têm o papel preciso de introduzir assimetrias insuperáveis e de excluir reciprocidades (...) Além disso, enquanto os sistemas jurídicos qualificam os sujeitos de direito, segundo normas universais, as disciplinas caracterizam, classificam, especializam; distribuem ao longo de uma escala, repartem em torno de uma norma, hierarquizam os indivíduos uns em relação aos outros, e, levando ao limite, desqualificam e invalidam. De qualquer modo, no espaço e durante o tempo em que exercem seu controle e fazem funcionar as assimetrias de seu poder, elas efetuam uma suspensão, nunca total, mas também nunca anulada, do direito (Foucault 1975/1986: 195).

Para Foucault (1975/1986) o exame manteve-se bem próximo do poder disciplinar que o originou, sendo um componente intrínseco das disciplinas. O exame, de sua perspectiva, passou por

(...) uma depuração especulativa, ao se integrar em ciências como a psiquiatria, a psicologia. E efetivamente, sob a forma de testes, de entrevistas, de interrogatórios, de consultas, o vemos retificar aparentemente os mecanismos da disciplina: a psicologia é encarregada de corrigir os rigores da escola, como a entrevista médica ou psiquiátrica é encarregada de retificar os efeitos da disciplina de trabalho. Mas não devemos nos enganar: essas técnicas apenas mandam os indivíduos de uma instância disciplinar a outra, e reproduzem, de uma forma concentrada, ou formalizada, o esquema de poder-saber próprio a toda disciplina (Foucault 1975/1986: 198).

O poder normalizador encontrou apoio na sociedade moderna nas formas concentradas ou disseminadas da rede carcerária, nos sistemas de in- 
serção, na distribuição, vigilância e observação, na criação de juízes da normalidade: há o professor-juiz, o médico-juiz, o educador-juiz, o assistente-socialjuiz, o psicólogo-juiz. Esses juízes procuram fazer reinar a universalidade do normativo, cada um, no ponto em que se encontra, "(...) submete o corpo, os gestos, os comportamentos, as condutas, as aptidões, os desempenhos" (Foucault 1975/1986: 266).

O autor nos mostra como, a partir da Idade Média, as novas (modernas) formas de punição e o aparecimento dos presídios atrelam-se ao nascimento das Ciências Humanas. Antes da Idade Média havia as masmorras (prisões subterrâneas) onde as pessoas eram postas e, tirando-se sua visibilidade, esquecia-se da sua existência, apagava-se a sua história e o seu ato (transgressor). O subsolo era o submundo, lugar sombrio, triste e lúgubre. Na Idade Média a prisão tornou-se a ante-sala da sala de julgamento. As pessoas enviadas para esse local morriam ou pagavam pela liberdade. Não existiam espaço e tempo para o confinamento e a situação do transgressor deveria ser rapidamente solucionada. Com o capitalismo mudaram as condições sociais. A prisão passou a ser um lugar de produção de conhecimento, de saberes sobre o homem. Com o êxodo rural passou a existir um grande contingente de pessoas nas cidades e, como corolário, passou a existir a necessidade de classificação (que deveria obedecer a uma lógica), nas escolas, nas fábricas, nos quartéis, nas prisões e nas diferentes instituições disciplinares. A punição passou a ser terapêutica, pois não mais punia/ culpava o ato (transgressor). Passaram a ser corretivas todas as práticas ritualísticas sobre o corpo que antes tinham como objetivo culpar o ato e fazer com que o sujeito expiasse a infração cometida. Essas novas práticas, técnicas reabilitadoras e ortopédicas, segundo Foucault (1975/1986), pretendiam consertar a vida (do sujeito) e não o ato. Nesse contexto aparece o embrião do que se chamaria de Psicologia. As práticas disciplinares e as discursividades das disciplinas começaram a se produzir quase ao mesmo tempo. As práticas de escrita passaram a se converter em técnicas de exame, de registro. Saiu de cena a infração (anteriormente importante) e criou-se o delinqüente, algo abstrato e supra sujeito. Antes o sujeito era morto pelo que fez. Agora a vida dele é o foco de análise, de atenção e de cuidado. Esse processo tornou público o julgamento. Nas instituições, um grupo de pessoas passou a ter acesso a história do sujeito (através dos prontuários e/ou pastas). É essa mudança que possibilitou o desen- 
volvimento das Ciências Humanas e a discursividade que vai compor a Psicologia, a Sociologia, etc ${ }^{1}$.

Também nos hospitais passam a ser classificados os indivíduos, separam-se os portadores de doenças infecto-contagiosas, as mulheres grávidas, etc. Como efeito desses processos de classificação e esquadrinhamento aparece o conceito de normal. Ou seja, o anormal fabrica o normal. Na Idade Média existiam as técnicas de punição que, com o passar do tempo, se converteram em práticas ortopédicas de correção, ganhando assim outro estatuto, outra conotação. Mas, no novo sistema de escrever sobre o sujeito, de olhar o sujeito, a punição passou a ser feita à luz do dia. Antes o sujeito era queimado na masmorra, agora se faz nele o eletrochoque nos hospitais. Assim, as práticas punitivas são legitimadas.

Foucault relaciona, assim, a normalização e o saber da Psicologia à disciplina e às instituições, considerando que

a prática que normaliza à força o comportamento dos indisciplinados ou dos perigosos pode ser por sua vez "normalizada" por uma elaboração técnica e uma reflexão racional. A técnica disciplinar torna-se uma "disciplina” que, também, tem sua escola. A certidão de nascimento da psicologia científica segundo os historiadores das ciências humanas é passada com data dessa época (...) na formação e no crescimento da psicologia, o aparecimento desses profissionais da disciplina, da normalidade e da sujeição (...) os controles da normalidade eram (...) fortemente enquadrados por uma medicina ou uma psiquiatria que lhes garantiam uma forma de "cientificidade”; estavam apoiados num aparelho judiciário (...) Assim, ao abrigo dessas duas consideráveis tutelas e aliás servindo-lhes de vínculo, ou de lugar de troca, desenvolveu-se continuamente até hoje uma técnica refletida do controle das normas (Foucault 1975/1986: 259-260).

A Psicologia, com pouco mais de cem anos, distribui-se por todo o corpo social e forma sobre os indivíduos um aparelho completo de observação, registro e anotações, constituindo um saber que se acumula e se centraliza.

1 De acordo com Foucault, isso é válido para França, Alemanha e Inglaterra. O autor limita-se a discutir os processos punitivos nesses contextos. 


\section{Metodologia de investigação}

Como metodologia de análise, adoto o Paradigma Indiciário, método interpretativo centrado nos resíduos e nos dados marginais como lugar privilegiado de reflexão. Esses dados marginais, que possibilitam momentos abdutivos, revelam sujeitos reais (e não ideais ou universais) e comportamentos singulares. Esse paradigma, discutido em Ginzburg (1986), emergiu por volta do final do século XIX apesar de suas raízes serem muito antigas e estarem localizadas em hábitos milenares da humanidade, nos quais o homem

(...) aprendeu a reconstruir as formas e movimentos das presas invisíveis pelas pegadas na lama, ramos quebrados (...) Aprendeu a farejar, registrar, interpretar e classificar pistas. Aprendeu a fazer operações mentais complexas com rapidez fulminante, no interior de um denso bosque ou numa clareira cheia de ciladas (...) o caçador teria sido o primeiro a "narrar uma história" porque era o único capaz de ler, nas pistas mudas (se não imperceptíveis) deixadas pela presa, uma série coerente de eventos (Ginzburg 1986: 151-152).

O Paradigma Indiciário encontrou implícita legitimação em diferentes esferas de atividades: medicina, psicanálise, historiografia, política, olaria, carpintaria, marinha, caça, pesca, entre outras. As ciências que partem desse método, denominadas indiciárias, se apóiam em sintomas, pistas, detalhes ou lapsos e se caracterizam por serem essencialmente qualitativas. Assim, os elementos imponderáveis com que lidam não são apreensíveis através de testes ou de esquemas previamente construídos. Discutindo os modos de fazer ciência dessas disciplinas, Ginzburg observa que

o grupo de disciplinas que chamamos de indiciárias (...) não entra absolutamente nos critérios de cientificidade deduzíveis do paradigma galileano. Trata-se, de fato, de disciplinas eminentemente qualitativas, que têm por objeto casos, situações e documentos individuais, enquanto individuais, e justamente por isso alcançam resultados que têm uma margem ineliminável de casualidade (...) ninguém aprende o ofício de conhecedor ou de diagnosticador limitando-se a por em prática regras preexistentes. Nesse tipo de conhecimento entram em jogo elementos imponderáveis: faro, golpe de vista, intuição (Ginzburg 1986: 156-179).

Proposto esse novo modelo de se fazer ciência, diferente daquele imposto pelas ciências exatas, naturais e positivistas - nas quais importam os resultados e as comprovações a que se pode chegar - redefiniu-se a noção de rigor científico, que passou a ser construído pela relevância dos dados 
analisados e não mais por comprovações estatísticas ou matemáticas (importantes para os testes e exames). O que caracteriza o tipo de análise qualitativa inerente ao Paradigma Indiciário é a possibilidade de olhar para a constituição dos sujeitos (singulares) na tentativa de compreender os dados (únicos).

\section{Apresentação e análise do corpus}

O corpus foi obtido a partir de atendimentos psicológicos realizados em um Ambulatório de Psicologia. Em exercício profissional que teve duração de um ano (entre fevereiro de 1996 e janeiro de 1997), minha tarefa única, na condição de psicóloga recém-formada, consistira em elaborar psicodiagnósticos de crianças (de 4 a 14 anos) encaminhadas pelas escolas, pelas famílias, por médicos (especialmente neurologistas), psicólogos, pedagogos, fonoaudiólogos, etc. Na obtenção dos dados tive o objetivo de registrar as diversas marcas escritas presentes nos processos de psicodiagnósticos das dificuldades de aprendizagem, de testes psicológicos a escrita de crianças (cf. Caron, 2000).

Apresentarei textos escritos de 4 (quatro) crianças: textos que são parte de um teste ${ }^{2}$ e textos "espontâneos". Os dados foram obtidos em dois momentos distintos. Num momento, usei a linguagem estereotipada do teste que constava tão somente de quatro passos para a investigação da escrita da criança, que são:

a) escrita de três palavras à escolha da criança;

b) cópia das palavras lidas vaso lata menino;

c) escrita das frases ditadas a menina gosta de brincar e o menino vai buscar a bola no quintal;

d) escrita das palavras ditadas barco cavalo escola.

Em todos esses passos não havia qualquer contextualização da escrita solicitada, o que espelha atividades de escrita comumente desenvolvidas na escola.

2 Analisarei parte de um teste (chamando atenção tanto à linguagem do teste como ao desempenho de duas crianças) usado nos processos de psicodiagnóstico no âmbito institucional, que é uma escala adaptada da bateria Luria-Nebraska. 
Num outro momento pretendia permitir às crianças falarem de si e do outro sem a definição prévia (conforme os prescritos nos manuais dos testes) do que seria escrito e/ou dito, promovendo o relacionamento dos parceiros que estabelecem contato. Nesses momentos considerava essencial operar significativamente com a linguagem para criar uma comunicação escrita que permitisse às crianças escreverem sobre suas realidades cotidianas - por exemplo, sobre futebol (pois as crianças gostam de esporte) e os times para os quais torcem.

A seguir serão apresentados os textos infantis com o intuito de reforçar minha hipótese de que a concepção de linguagem dos testes psicológicos é estereotipada e muito pouco permite de fato afirmar e/ou constatar. Escreve-se à toa, sem se saber por quê ou para quem. Comparando-se as escritas de teste de FC e JR com suas escritas espontâneas é possível perceber que, na segunda situação, aparecem as hipóteses lingüísticas das crianças. Já na situação de teste essas não surgem e as escritas podem sugerir ao investigador que as crianças já dominam (ou não) a linguagem escrita.

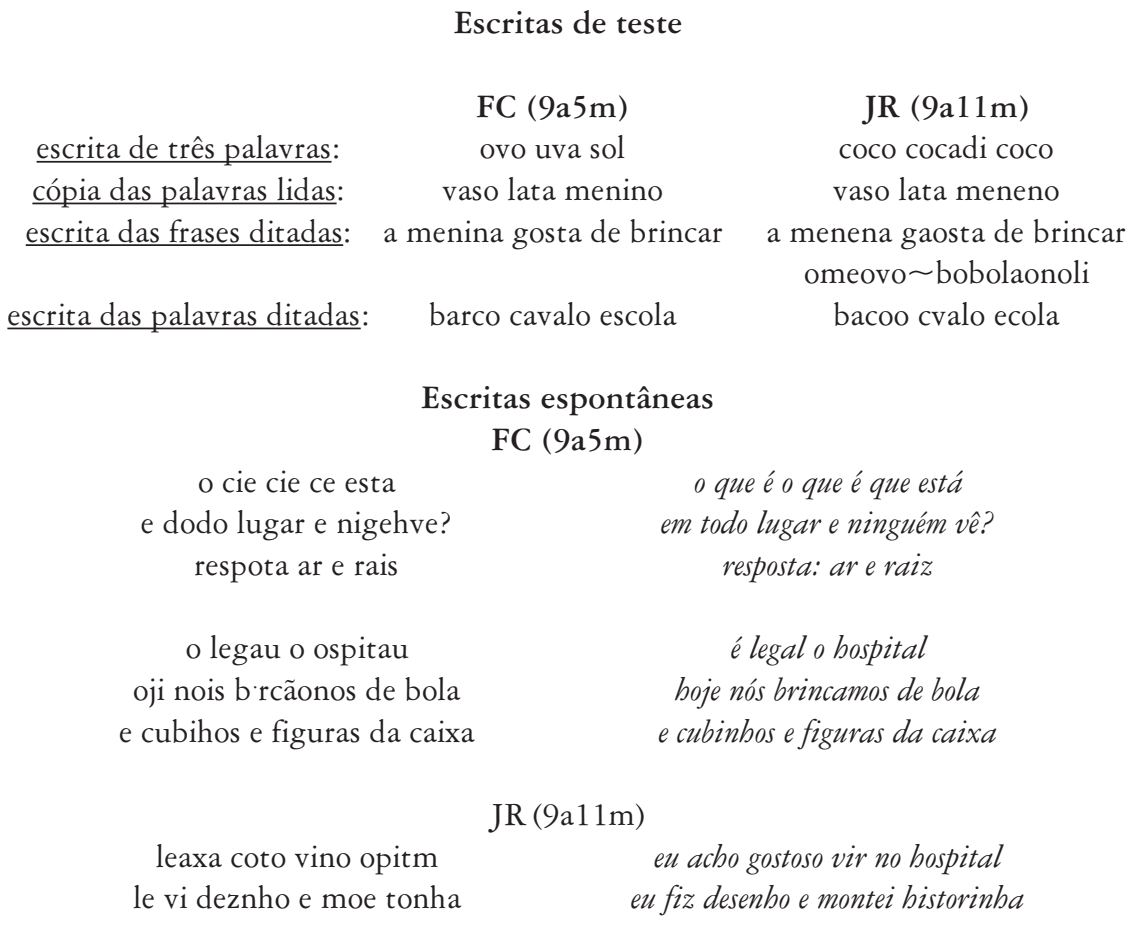


A escrita de teste de FC é correta. Mas, as hipóteses lingüísticas da criança aparecem na sua escrita espontânea: vemos, por exemplo, a sistematicidade - o que é o que é que a criança escreve o cie cie cie - com a qual sustenta a hipótese de que a letra $c$ é usada para representar o que; outra sistematicidade no uso da letra $u$ na escrita de legau e ospitau; e a hiposegmentação em nigehve (ninguém vê) ${ }^{3}$.

JR escreve como se o lápis pesasse e não lhe fosse familiar ao manuseio, sua letra pequena é quase ilegível, mas permite antever um conhecimento em construção. A criança dá pistas de que está construindo um saber sobre a linguagem escrita. Há problemas ortográficos sim. No entanto, eles não são aleatórios (ver como JR grafa o eu como le nas duas vezes em que escreve a palavra) e não podem ser confundidos com problemas de linguagem, pois a sintaxe e a semântica estão preservadas já que a criança dispõe as palavras corretamente na frase, há uma relação lógica entre as frases e há o uso correto das palavras - ainda que escritas erradas - garantindo o significado. A escrita de estorinha como tonha indicia uma provável pronúncia desta palavra como toinha. É possível perceber que a criança segmenta palavras, demonstra perceber as sílabas e constrói hipóteses sobre a escrita.

$\mathrm{Na}$ escrita espontânea e na escrita de teste (ainda que desconsideradas nas análises que se fazem dos testes) aparecem as hipo e hiper segmentações, indícios das hipóteses das crianças sobre a escrita, como na frase $o$ menino vai buscar a bola no quintal (omeovo bobolaonoli), eu acho (leaxa) e vir no (vino). As hipo e hipersegmentações, de acordo com Silva (1989), decorrem de uma tentativa das crianças de representar graficamente a expressidade discursiva, através de estratégias de segmentação baseadas na fala. Segundo o autor "(...) a sua representação ortográfica tende a refletir unidades conforme ela as segmenta no seu discurso oral" (p. 10). Tomando por base o já constituído e à sua maneira fazendo descobertas, as crianças fazem reformulações do sistema lingüístico. Ao permitir que as crianças falem (escrevam) de si, elas parecem encontrar novas opções na/da linguagem.

\footnotetext{
3 Silva (1989) mostra que ao escrever a criança segmenta a escrita de acordo com as hipóteses que formula sobre a pronúncia daquela parte do enunciado, propondo soluções pessoais para partes do discurso, incorporando segmentações observadas antes, na própria escrita e na cartilha. As mesmas unidades gráficas aparecem segmentadas de modos diferentes e conflitantes, comprovando que há elaboração e reelaboração contínua de suas representações lingüísticas. Tal processo permite à criança chegar à sistematização das formas lingüísticas (orais e escritas).
} 
Essas, no entanto, os testes não autorizam, não consideram e rejeitam tomar como ponto de partida para a investigação e análise, procedendo a uma homogeneização dos sujeitos. Os dados demostram que as crianças estão adquirindo a escrita, trabalhando com e sobre ela ${ }^{4}$.

É grande a diferença entre a escrita do teste e a escrita produzida em situação discursiva, em que as crianças são colocadas numa situação de escrever textos que comportam palavras não necessariamente presentes na cartilha e nos exercícios escolares; erram do ponto de vista da escola, mas esses mesmos erros é que dão visibilidade às hipóteses das crianças, ao trabalho que exercem com a escrita ( $c f$. Franchi, 1977). Por outro lado, na situação de teste, não há espaços para a emergência das hipóteses lingüísticas das crianças e, ao investigador desatento, a escrita pode sugerir que a criança sabe a ortografia das palavras, todas elas bastante comuns em cartilhas utilizadas em situações tradicionais de alfabetização (tais como ovo, uva, sol, barco, cavalo e escola).

A respeito dos dados lingüísticos de que partem os manuais usados para diagnóstico, Coudry (1987) observa que “(...) são palavras e algumas frases isoladas e pendentes" (p. 156) e a conseqüência disso é que um fenômeno patológico como a dificuldade de aprendizagem "(...) é conseqüência do modo como a instituição escolar, que por sua vez se liga ao poder e a cultura [dominante], encara a alfabetização (...) voltada para a língua padrão, centrada na aquisição de uma técnica e na exclusão da criança como um sujeito atuante no processo de construção do objeto escrito" (Coudry 1987: 155). Mas, para se avaliar o processo de aprendizagem, é preciso cuidado, rigor e profundidade. Em outras palavras, são necessárias posições teóricometodológicas explícitas. Por se tratar de avaliação de sujeitos, é necessária uma teoria de linguagem que os considere e tudo que decorre dessa consideração.

Observemos as escritas de RD e KS.

\footnotetext{
4 Essa concepção de trabalho, como um lugar privilegiado para se ter acesso ao sujeito que escreve e aprende, origina-se em Franchi (1977).
} 


\section{Escritas espontâneas}
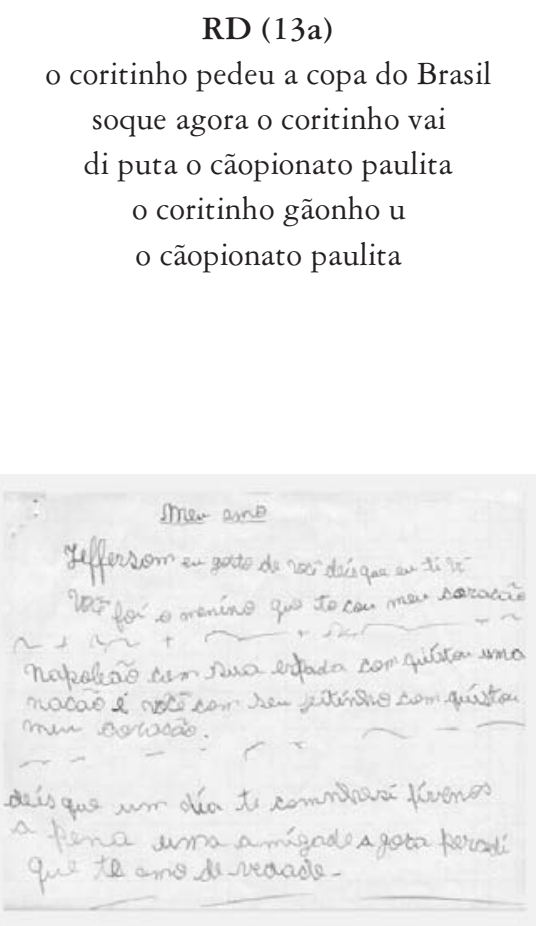

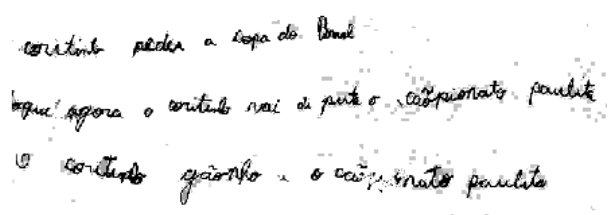

o cãopionato paulita

Vemos que as produções escritas livremente pelas crianças contêm indícios que permitem suspeitar da ocorrência de uma sistematização em curso e indicam uma característica essencial do processo de aquisição da linguagem, apontada em Figueira (1996), que resulta no reconhecimento da "precedência do desenvolvimento comunicativo sobre o desenvolvimento estritamente lingüístico (o domínio de regras e relações)" (p. 59). As crianças usam a escrita, ensaiam, falam de si. Nesses momentos, as crianças podem escrever sobre futebol, como faz RD (13a), ou fazer poesia e declarar o que sentem, como faz KS (11a8m). Mayrink-Sabinson lembra que para a criança

(...) a escrita não é essa coisa fria, que serve à memória, que quebra barreiras de espaço e tempo (...) a escrita é "mágica”, é "poder". Ela aproxima , permite a interação e a interlocução. Ela dá poderes a quem a manipula, oferecendo argumentos irrefutáveis. Ela também serve de consolo (1990: 438). 
A relevância desses dados, cuja emergência é única, reside no fato de eles permitirem considerar a manipulação e o uso da linguagem pelas crianças; em outras palavras, nas interlocuções estabelecidas com as crianças é permitido que falem (escrevam) de si. Desse modo, as crianças parecem encontrar novas opções na/da linguagem, as quais os testes psicodiagnósticos não autorizam e rejeitam tomar como ponto de partida para a investigação. É possível perceber, nos dados apresentados, acontecimentos recorrentes no processo de aquisição de escrita, decorrentes de uma concepção específica e simplificada de linguagem escrita. Mas, é evidente que as crianças são capazes de organizar idéias nos seus textos. Dizer o contrário é acreditar que as idéias são uma contraparte exata das frases (cf. Possenti 1992).

Dizer que essas crianças têm dificuldades de aprendizagem é contribuir para o estabelecimento de classificações rigorosas, assegurando o funcionamento automático do poder e permitindo a determinação da inserção dos corpos no espaço, a distribuição dos indivíduos em relação mútua, a organização hierárquica, o panóptico, a emergência dos processos técnicos e científicos de exclusão.

A escrita dessas crianças faz pensar, sobretudo, no nível de letramento que dispõem ( $c f$. Kleiman 1998). Vale a pena chamar a atenção para o fato de que a escrita dessas crianças é esperada para as crianças das primeiras séries. Seriam elas, porque são mais velhas (entre 9 e 13 anos), encaminhadas ao psicólogo como "problemas" por causa da escrita que não corresponde ao esperado (pela norma)?

Os testes psicológicos pretendem ser uma medida precisa, matematizável, das condições internas dos sujeitos e do funcionamento de suas estruturas neurológicas, psicológicas e motoras: atenção, concentração, raciocínio lógico, entre outras. Subjacente à construção de tais instrumentos há a crença de que tais aspectos (humanos) são concretos e palpáveis. No entanto, é fácil perceber que o teste mede a expressão de um estado e não o estado em si ( $c f$. Moysés e Collares 1997). É preciso considerar as condições do sujeito no momento de aplicação do teste, a linguagem utilizada pelo teste e a que o sujeito domina e/ou usa (ou seja, a variedade lingüística do sujeito e do objeto - teste), seu meio ambiente, e uma infinidade de variáveis que podem intervir no ato e na medida, que é, em última instância, apenas uma expressão do estado do sujeito naquele momento. 
Coudry (1986/1988) faz uma discussão acerca das relações dos sujeitos com a linguagem nos procedimentos avaliativos e analítico-descritivos disponíveis no contexto dos diagnósticos. De um modo geral, de acordo com autora, os testes apresentam as seguintes inadequações:

descontextualização das tarefas de linguagem propostas, simulando situações artificiais para uma suposta atividade lingüística; predominância de tarefas metalingüísticas que, embora necessárias para o diagnóstico, não podem substituir atividades lingüísticas e a consideração dos processos epilingüísticos e a reconstrução da linguagem (...); o fato de que a natureza das tarefas propostas correspondente a exercícios fundados na língua escrita, com um forte compromisso escolar (...) se reduzem a técnicas de abordagem do fenômeno para levantar fatos necessários à descrição acadêmica (...); insuficiência nos resultados empíricos: a perspectiva teórica reducionista do fenômeno da linguagem acaba por restringir os fatos justamente àqueles que não são nem os mais significativos nem os mais relevantes para caracterizar as dificuldades (...) e fornecer subsídios para o acompanhamento (Coudry 1986/1988: 6).

Para essa autora, é a falta de uma perspectiva discursiva de linguagem que impede que se revelem aspectos importantes das dificuldades, que não são observáveis nos resultados obtidos nos testes. A concepção de linguagem de que partem os testes parece excluir o sujeito real, aquele que opera e trabalha e, em nome da precisão, parece acreditar em indivíduos estáticos.

No processo de psicodiagnóstico, de classificação, é evidente a aproximação entre os sistemas disciplinares e os saberes da Psicologia. Entram em funcionamento operações bem distintas, apontadas por Foucault (1975/ 1986): relacionam-se os atos, os desempenhos, os comportamentos singulares, a um conjunto que é ao mesmo tempo campo de comparação, espaço de diferenciação e princípio de uma regra a seguir, de uma norma; diferencia-se os indivíduos uns em relação aos outros e em função dessa regra de conjunto, que funciona como base mínima; mede-se em termos quantitativos e hierarquiza-se em termos de valor as capacidades, a natureza dos indivíduos; através dessa medida valorizadora faz-se funcionar a coação de uma conformidade a realizar; e, finalmente, traça-se o limite que define $a$ diferença em relação a todas as diferenças, a fronteira externa do anormal. Para o autor, nesse processo "a penalidade perpétua que atravessa todos os pontos e controla todos os instantes das instituições disciplinares compara, diferencia, hierarquiza, homogeniza, exclui. Em uma palavra, ela normali$z a "$ (Foucault 1975/1986: 163). 
Ao buscar qualificar, classificar, submeter a uma norma, o psicólogo responde a um ritual, dá visibilidade a sobreposição das relações de poder e saber. O psicólogo acredita encontrar confirmações nos resultados dos testes, nos quais busca um saber sobre os indivíduos, sustentado por um ritual constantemente renovado que permite transmitir seu saber e levantar um campo de conhecimentos sobre os sujeitos. Os testes supõem um mecanismo que liga a formação de saber a um exercício de poder.

Os testes dão visibilidade aos indivíduos, os diferencia, combina as técnicas da hierarquia, normaliza, é uma vigilância que permite classificar e punir. É por isso que em todos os dispositivos de disciplinas, o exame é altamente ritualizado. Nele reúne-se a cerimônia do poder e a forma da experiência, a demonstração da força e o estabelecimento da verdade. Assim, "a superposição das relações de poder e das de saber assume no exame todo o seu brilho visível” (Foucault 1975/1986: 165).

\section{Considerações Finais}

Como resultado dos testes são produzidos os psicodiagnósticos, instrumentos de poder que determinam o lugar que as crianças podem e devem ocupar. Em outras palavras, ao apontar a anomalia da criança, o psicodiagnóstico cumpre uma de suas funções, conforme apontada por Foucault (1975/1986): dá aos mecanismos da punição legal um poder justificável sobre os indivíduos, sobre aquilo que eles são. O psicodiagnóstico introduz as anomalias no campo dos objetos susceptíveis de um conhecimento científico. O uso de uma determinada armature de savoir (cf. Foucault 1971), da Psicologia, é refletido no uso que essa ciência faz de testes - em detrimento de análises qualitativas que consideram o processo e o produto.

Legalmente o psicodiagnóstico é o único documento que autoriza a entrada e a saída de crianças nas conhecidas Salas Especiais existentes na Rede Pública de Ensino. Nos processos de psicodiagnóstico aqui considerados, uma cópia do documento (laudo ou psicodiagnóstico) era anexada ao Prontuário Médico da criança, uma era dada à família e outra era enviada aos professores ${ }^{5}$. Revestida desse (instrumento de) poder, a instituição

\footnotetext{
5 Como corolário, muitas vezes a interação de professores e alunos passa a resultar na resistência e no conflito: à assimetria que é constitutiva do discurso escolar acrescenta-se outra que advém da condição do aluno considerado doente, anormal (cf. Kleiman 1998).
} 
mandava de volta a criança ao sistema público de ensino, à vida, sem a possibilidade de diálogo entre psicólogos e crianças. Assim, uma vez assinado o psicodiagnóstico, todas as relações psico-pedagógicas das crianças levam sua marca, na maioria das vezes indelével.

Para Foucault (1975/1986), essas técnicas de poder como um processo de saber permitem a medida das quantidades e a análise dos movimentos: sob a forma da taxinomia, essas medidas tem por função caracterizar (e em conseqüência reduzir as singularidades individuais) e constituir classes. Para o autor, a taxinomia “(...) é a condição primeira para o controle e o uso de um conjunto de elementos distintos: a base para uma microfísica de um poder que poderíamos chamar celular" (Foucault 1975/1986: 136). Assim, desde o século XVIII, a taxinomia é tanto uma técnica de poder como um processo de saber.

Procedendo dessa forma, os psicodiagnósticos oficializam o fracasso ao invés de permitirem que o sujeito conheça suas dificuldades e possa, assim, lidar com elas. Representando valores de homem e sociedade, o psicodiagnóstico interfere negativamente na vida do sujeito rotulando-o com várias incapacidades Ao desconsiderar fatores constitutivos da linguagem e de seu papel frente aos demais processos cognitivos, veicula estigmas em crianças que fogem ao esperado quando se trata de aprendizagem escolar. Atuando como um mecanismo de poder, silencia as questões culturais e históricas presentes no contexto em que se insere o ensino e a aprendizagem.

Assim, para findar, defendo a idéia da necessidade de uma transformação profunda nos modos de ensinar a Psicologia, transformação relaciona$\mathrm{da}$, de alguma maneira, com outra igualmente profunda nos modos de organizar a sociedade e seu modelo econômico, pois acredito, como sustenta Possenti, que "a alteração dos rumos políticos poderia produzir como um de seus efeitos que a escola não continuasse sendo tão grosseiramente, pelo menos, uma maquinaria destinada a excluir" (1992: 21).

E-mail: monicacaron@yahoo.com.br Recebido em setembro de 2003 Aprovado em fevereiro de 2005 


\section{REFERÊNCIAS BiBLIOGRÁFICAS}

Caron, Monica Filomena. 2000. As Relações da Escola com a Sociedade nos Processos de Diagnostícar/Avaliar. Dissertação de Mestrado do Instituto de Estudos da Linguagem - Unicamp.

Coudry, Maria Irma Hadler. 1986. Diário De Narciso - Discurso e Afasia. São Paulo: Martins Fontes. 1998.

. 1987. Dislexia: Um Bem Necessário. Estudos Lingüísticos, XIV Anais de Seminários do GEL. Campinas, SP, vol. 1: 150-157.

Figueira, Rosa Attié. 1996. O Erro como dado de Eleição nos Estudos de Aquisição da Linguagem. In: Maria Fausta P. CAstro (Org.). O Método e o Dado nos Estudos da Linguagem. Campinas, SP: Editora da Unicamp.

Foucault, Michel. 1975. Vigiar e Punir. Petrópolis: Vozes. 1986. . 1971. L'ordre Du Discours. Paris: Gallimard.

FranchI, Carlos. 1977. Linguagem - Atividade Constitutiva. AlmanaqueCadernos de Literatura e Ensaio. São Paulo: Brasiliense: 9-27.

Ginzburg, Carlo. 1986. Mitos, Emblemas e Sinais. São Paulo: Companhia das Letras.

KLeiman, Ângela. 1998. Ação e Mudança na Sala de Aula: Uma Pesquisa Sobre Letramento e Interação. In: Roxane Rojo (Org.). Alfabetização e Letramento. Campinas, SP: Mercado de Letras.

Mayrink-Sabinson, Maria Laura Trindade. 1990. As Funções da Escrita para a Criança que ainda não sabe Ler/Escrever". Anais da XX Reunião Anual de Psicologia da Sociedade Brasileira de Psicologia.

Moysés, Maria Aparecida Affonso \& Cecília Azevedo Lima Collares. 1997. Inteligência Abstraída, Crianças Silenciadas: As Avaliações de Inteligência. In: Psicologia USP: Psicologia e Razão Instrumental. São Paulo, SP, vol. 8, Número 1: 63-89.

Possenti , Sírio. 1992. Enunciação, Autoria e Estilo. Revista da FAEBA. Salvador: UNEB.

SiLva, Ademar da. 1989. A Relação entre a Fala e a Segmentação na Escrita

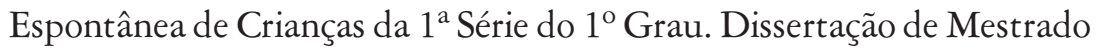
do Instituto de Estudos da Linguagem - Unicamp. 